\title{
The Proximal Zone of Intercultural Development (PZID)
}

\begin{abstract}
:
This article presents results of a comparative analysis of intercultural experiences between French and Singaporean participants. France and Singapore were chosen as research fields because of their difference in terms of the management of cultural otherness: a universalist cultural model for France and a pluralist cultural model for Singapore.

Based on an online questionnaire addressing the intercultural experience of the participants, a quantitative analysis allows us to identify singular differences between the French and Singaporean participants. A particularity of the Singaporean context leads us to think about the concept of the proximal zone of intercultural development (PZID) that we will develop in this article.
\end{abstract}

Keywords: proximal zone, intercultural, development 


\section{The Proximal Zone Intercultural Development (PZID)}

\section{Introduction and background}

This article presents results from a cross-cultural analysis of intercultural experiences of French and Singaporean participants. Our research took place on two geographical areas, France and Singapore. Without going into a strict dichotomous approach, we can speak of a universalist cultural model for France and of a pluralist cultural model for Singapore as " two major methods of responding to migration questions : one which is inscribed in the context of pluralist societies where the origin of individuals is made visible in the public space and can serve either as a group federation indicator or as an identification parameter for public actions; and one which fits into the context of universalist societies where the origin of individuals belongs to the private sphere and can neither serve as a register of identification for public authorities, nor be mobilized by groups to organize themselves" (Escafre-Dublet, 2015) .

Based on an online questionnaire addressing the intercultural experience of participants, a quantitative analysis $(\mathrm{N}=246)$ allows us to identify singular differences between the French and Singaporean environments. A particularity of the Singaporean context leads us to think about the concept of proximal zone of intercultural development (PZID) that we will develop in this article.

\section{Categorizing the intercultural experience}

We thus proceeded to a comparison of intercultural experiences between the French and Singaporean participants. Concerning the interculturation process, we consider it at three levels where the (multi)cultural background can impact individuals : the intrapsychic level (metabolizations resulting from the contact of cultures at the individual level), the intersubjective level (at the level of the same cultural group) and the intergroup level (at the level of the same cultural group). different cultural groups).

Our approach is based on a questionnaire proposed online on our two geographical areas and exploring the intercultural experiences of the participants. Our sample consists of 246 participants (144 in France and 102 in Singapore). The research was granted approval for the ethical evaluation from the Nanyang Technological University (NTU) of Singapore (IRB-2018-03-021).

Previous researches (Oulahal, 2021; Oulahal, 2019; Oulahal, Denoux, and Teyssier, 2018; Oulahal, Denoux, Teyssier, et al, 2018; \& Oulahal Denoux, 2018, 2020) highlighted that intercultural experiences can be split down according to different characteristics of the culture contacts that we present below :

- The level where the contact of cultures is located : intrapsychic, intersubjective, intergroupal. 
- The temporality of the contact of cultures: the goal here is to define the period of life during which the individual experienced the contact of cultures as well as the duration of this contact. A preliminary qualitative analysis (Oulahal \& Denoux, 2018 ; Oulahal \& Denoux, 2020) allowed us to characterize the culture contact temporality as either an early interculturation (before the age of 6 years old) or a late interculturation (after the age of 6 years old). Such categorization echoes results from language sciences that distinguish early and late bilingualism and identify variability in cognitive processes they generate (Singleton, 2003).

As such, we propose the concept of pattern also derived from the epistemology of language sciences. Indeed, the language use models can evolve according to an individual's life course (Ardila and Ramos, 2010). In the case of bilingualism, the two languages can be associated with different social contexts and life situations. Thus, the second language may have been acquired later in life, in connection with a new professional activity or a migration. The first language and the second language can be used simultaneously throughout life or during specific periods of life. Furthermore, both the first and the second language may have been acquired quite early in the life course. The patterns of first language and second language use can vary over the lifetime (Ardila \& Ramos, 2008).

We thus propose to work on the concept of "interculturation patterns" and to consider that, for each individual, the acquisition of various cultures can be carried out according to different methods, just as it has been proposed for the acquisition of languages. After our preliminary work, we can propose the following interculturation patterns.

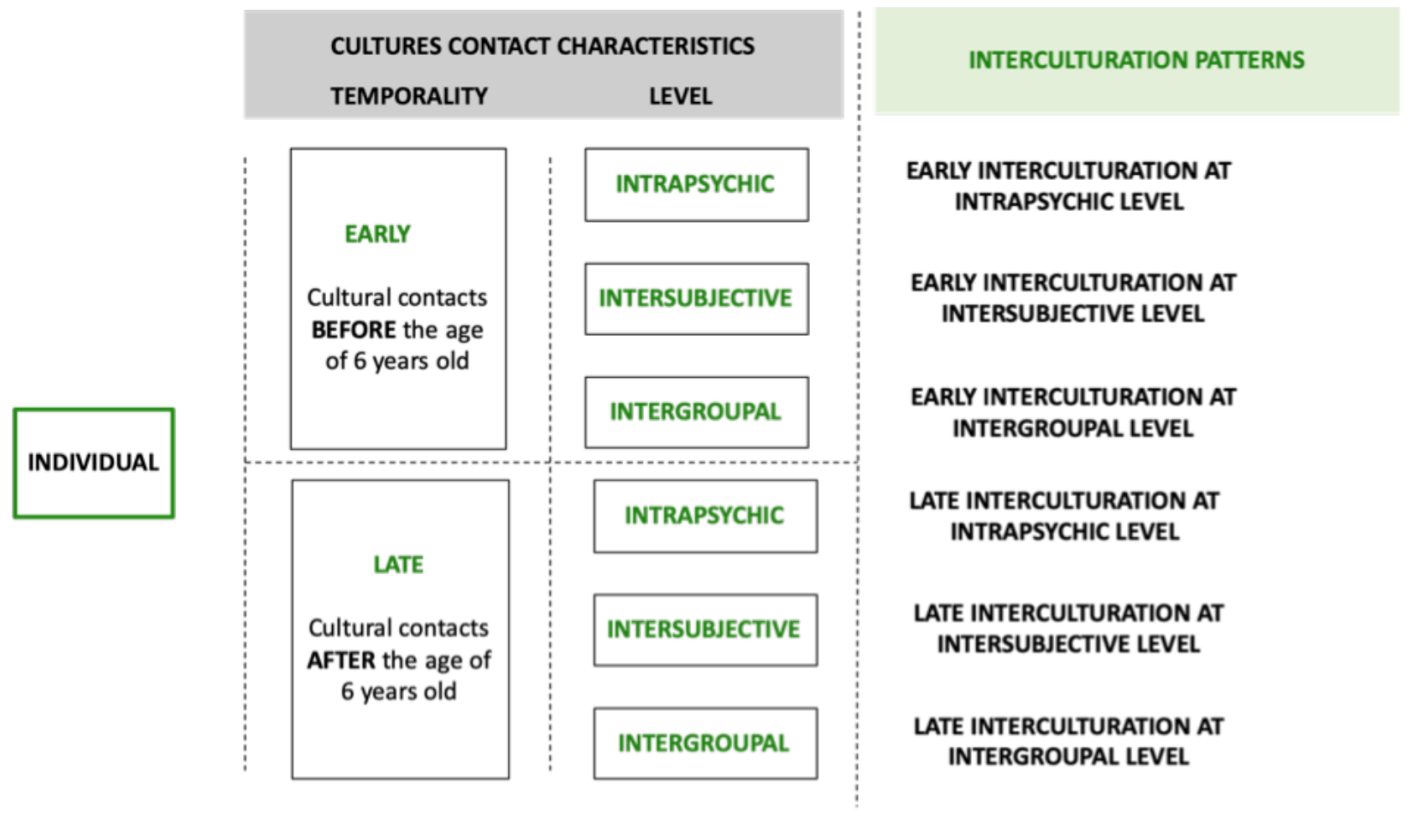


In order to build this pattern, our survey included a series of questions addressing the contact of cultures in the different periods of the participants' lives. Although our proposal was to consider the age of 6 to distinguish the interculturation experience as early or late, we wanted to get more information by considering different periods of life, according to the identity model proposed by Erikson (1968 / 2006). In this perspective, identity is considered as the synthesis of the various identifications an individual experienced from birth to adulthood and develops throughout life. At the heart of this model are inscribed a succession of stages which allow the individual to develop his identity. To describe this lifelong journey, Erikson proposes eight stages of psychosocial development and each stage is characterized by a crisis an individual must face by choosing between two opposite terms of an alternative. The good resolution of this crisis allows the subject to progress, in relation to his environment, in his development and to consolidate his identity construction.

Thus, a cycle of questions is proposed to participants in our survey in order to identify the temporalities of an intercultural experience (between 0 and 6 years old, between 6 and 12 years old, between 12 and 18 years old and finally from 18 years old) as well as the level of this experience, the intersubjective level being considered in the family and friendship contexts while the intergroup level is considered in the context of the general environment of the participant (city, country).

The questionnaire items were presented as follows:

- When I was between 0 and 6 years old, I had several cultures

- When I was between 0 and 6 years old, among my relatives (family, friends), several cultures were represented

- When I was between 0 and 6 years old, I lived in an environment (city, country) where several cultures came together

- When I was between 6 and 12 years old, I had several cultures

- When I was between 6 and 12 years old, among my relatives (family, friends), several cultures were represented

- When I was between 6 and 12 years old, I lived in an environment (city, country) where several cultures came together

- When I was between 12 and 18, I had several cultures

- When I was between 12 and 18 years old, among my relatives (family, friends), several cultures were represented

- When I was between 12 and 18 years old, I lived in an environment (city, country) where several cultures came together

- Since I was 18, I have several cultures

- Since I was 18 years old, within my family (family, friends), several cultures are represented

- Since I was 18, I have lived in an environment (city, country) where several cultures come together 


\section{Presentation of the results}

On the basis of the responses obtained during the data collection phase $(\mathrm{N}=$ 246), we compare the intercultural experiences of the French and Singaporean participants in the different periods of life.

\section{General analysis}

Considering France as a universalist monocultural environment and Singapore as an institutionalized multicultural environment, we see that no difference has been identified for the intersubjective level of the interculturation experiences. Moreover, from 18 years old, our participants responses showed no difference between France and Singapore with respect to intersubjective and intergroupal interculturation.

Tableau 1 - Interculturations at all ages

\begin{tabular}{|l|c|c|c|c|c|}
\hline \multicolumn{6}{|c|}{ INTERCULTURATION DECLARED AT ALL AGES (IN\%) } \\
(In bold the significant differences identified during the statistical analysis) \\
\cline { 3 - 7 } & & $\begin{array}{c}\text { BEFORE } \\
6 \text { YEARS }\end{array}$ & $\begin{array}{c}\text { BEFORE } \\
12 \\
\text { YEARS }\end{array}$ & $\begin{array}{c}\text { BEFORE } \\
18 \\
\text { YEARS } \\
\text { OLD }\end{array}$ & $\begin{array}{c}\text { FROM 18 } \\
\text { YEARS OLD }\end{array}$ \\
\hline \multirow{2}{*}{ IntraPsychic Level } & France & 32 & 34 & 32 & 49 \\
\cline { 2 - 7 } & Singapore & 35 & $\mathbf{5 1}$ & $\mathbf{5 7}$ & $\mathbf{6 8}$ \\
\hline InterSubjective Level & France & 48 & 55 & 70 & 85 \\
\cline { 2 - 7 } & Singapore & 48 & 60 & 70 & 86 \\
\hline InterGroupal Level & France & 44 & $\mathbf{5 2}$ & $\mathbf{6 4}$ & 84 \\
\cline { 2 - 7 } & Singapore & $\mathbf{8 4}$ & $\mathbf{8 4}$ & $\mathbf{8 8}$ & 92 \\
\hline
\end{tabular}

The results of our quantitative analysis indicate that the only significant difference between the French and Singaporean samples from the age of 18 is at the level of intrapsychic interculturation, with $49 \%$ of the French participants and $68 \%$ of the Singaporean participants $\left(\chi^{2}(1,168)=5.622, \mathrm{p}=0.02\right)$. 
Between 6 and 12 years old, our quantitative analysis shows that the significant difference at the intergroupal interculturation level is confirmed between the French and Singaporean participants : $\chi^{2}(1,172)=26,472, p=0,000$ (before 6 years old), $\chi^{2}(1,168$ ) $=17.284, \mathrm{p}=0.000$ (before 12 years old), $\chi^{2}(1.168)=10.929, \mathrm{p}=0.001$ (before 18 years old). From the age of 18 , the difference is no longer significant between the French and Singaporean participants with regard to interculturation at the intergroup level ( $\chi^{2}(1.168)$ $=2.357, \mathrm{p}=0.125$ ).

The difference in interculturation at the intrapsychic level appears before 12 years old $\left(\chi^{2}(1.171)=4.519, \mathrm{p}=0.034\right)$ whereas it was not significant before 6 years $\left(\chi^{2}\right.$ $(1.172)=0.142, \mathrm{p}=0.706)$. This difference will remain significant for the other periods of life $: \chi^{2}(1.169)=5.431, \mathrm{p}=0.020$ (before 18 years old) and $\chi^{2}(1.168)=5.622, \mathrm{p}=$ 0.018 (from 18 years old). Thus, the period of life between 6 and 12 years seems unique in the individual intrapsychic integration of cultural plurality.

Although intersubjective interculturation also increased in the two samples, we did not find a significant difference. Moreover, interculturation at the intersubjective level does not seem to be able to explain on its own the significant difference at the intrapsychic interculturation level.

Table 1 suggests that the significant early intergroup interculturation in the Singaporean sample had a positive role in the intrapsychic interculturation level of the Singaporean participants. Thus, the interculturation within the family and friend environment (intersubjective level) wouldn't such a strong impact on the interculturaltion integration at the intrapsychic level. Rather, the intergroup interculturation level would have a stronger influence, especially in the case of Singapore and its institutionalized multiculturalism context.

We could also consider the role of the school in the integration of cultural plurality because it is between 6 and 12 years that the Singaporean participants' increase is the highest in the proportion of people declaring an interculturation at the intrapsychic level (Increase from 35 to $51 \%$ of the sample).

As we discussed above, a link could be made with the corresponding period in the stages of development of Erikson's model. The encounter with the group of peers carrying different cultural values could lead a child to consider the gaps and relations between the cultural systems encountered and his own cultural affiliations.

In any case, being born in a multicultural environment does not seem to have any influence in the interculturation at the intrapsychic level between 0 and 6 years old. In a way, family culture would remain at the center of the individual's life between 0 and 6 years old. The non-significant difference between France and Singapore over this period of life in intersubjective interculturation seems to go in this direction.

Our assumption is that intergroup interculturation would not have access to individuals between 0 and 6 years old and it would only be from 6 years old that 
intergroup interculturation would be perceived by individuals and would seem to have an effect on intrapsychic interculturation between 6 and 12 years old.

Finally, our results would indicate that the intrapsychic level is at the center of the contact of cultures matter. Because in the end, both in France and in Singapore, a large proportion of participants (over 84\%) indicate living in a close (family, friend) and global (city, country) environment where several cultures mixed together. The sole analysis of the multiculturalism of a national environment and/or family should not be considered as sufficient to characterize individuals' intrapsychic interculturation.

For example, we see in table 1 that $32 \%$ of the French participants and $35 \%$ of the Singaporean participants declared they had several cultures between 0 and 6 years old whereas they were $48 \%$ in the two countries to indicate having lived in a close environment (family, friend) where several cultures mixed together. Likewise, from the age of 18, 49\% and 68\% respectively say they have several cultures, while 85 and 86\% of them say they live in a close environment (family, friend) where several cultures mix together. .

\section{Discussion - Interculturation at the intergroup level as a proximal zone of intercultural development (PZID)}

As we indicated previously, although the intersubjective interculturation increases with the age in both French and Singaporean samples, it does not seem sufficient to explain the significant difference at the intrapsychic interculturation level. Two potential reasons could appear at this stage.

First of all, we think that intergroup interculturation " authorizes" individuals to integrate at the intrapsychic level an existing intersubjective interculturation from an early age. As France and Singapore are two different environments in terms of managing the cultures' contact, we believe that the respective country's policies may lead to a distancing or affirmation of intergroup interculturation. Thus, the metabolization of an intrapsychic interculturation could be more difficult in France.

However, the effect of intersubjective interculturation seems to remain limited. Indeed, even in large and equal proportions from the age of 18 (85\% in France and 86\% in Singapore), intersubjective interculturation does not seem to act in any way so as to bring closer French and Singaporean proportions of intrapsychic interculturation.

The second possibility could be that intersubjective interculturation has little connection with intrapsychic interculturation because it corresponds to the family environment "not chosen" by the subject. It would thus be mainly intergroup interculturation that would open the way for individuals towards a plurality of cultural affiliations, a plurality where individuals can get inscribed by their own personal choice. 
In either case, we find that intergroup interculturation would act as a catalyst for the intrapsychic integration of intercultural metabolizations and emergences. Without intergroup interculturation, nothing would be possible.

Intergroup interculturation enables the encounter of cultures but it must be recognized and encouraged so that cultural contacts can be integrated at the individual level of individuals involved. The intercultural identity of the Singaporean participants would echo the intercultural identity of their nation.

We propose the following graph to better highlight these changes and the convergence of intrapsychic and intersubjective interculturations from the age of 18 .

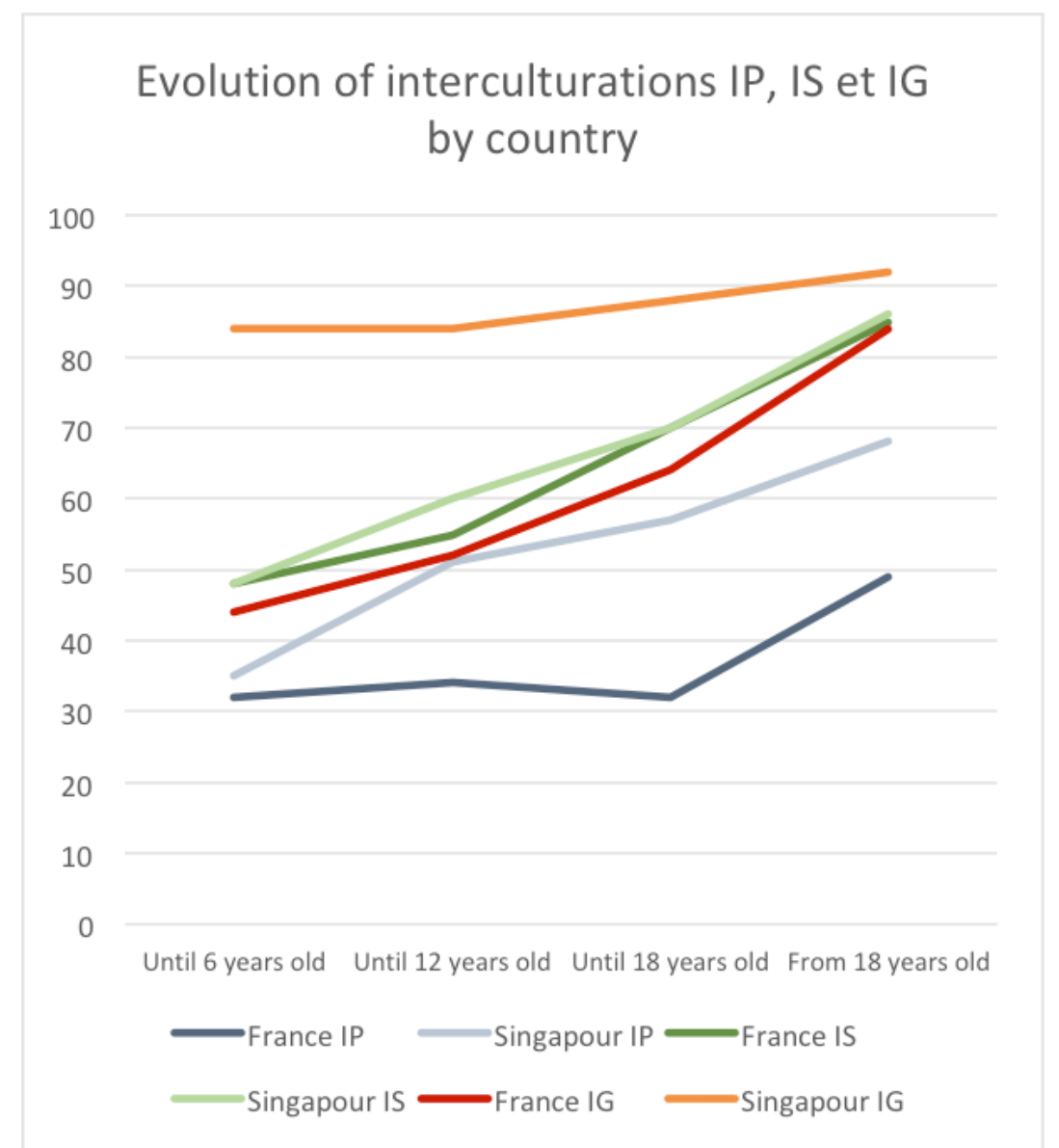

Figure 2 - Evolution of interculturations by country (IP : Intrapsychic; IS : Intersubjective ; IG : Intergroup)

Finally, our hypothesis would be that family has a less important effect in the psychic integration of cultural plurality than individuals' national environment. The contact of cultures within the close and intersubjective environment would be a basis of intrapsychic interculturation but intergroup interculturation would be the condition for the emergence of intrapsychic interculturation. And it is as such that we think of the contact of cultures at intergroup level as a proximal zone of intercultural development (PZID).

Considering the proximal zone of intercultural development, we can wonder if it would be possible for individuals to have a greater intrapsychic interculturation than those at the intersubjective and intergroupal levels. 
If we link our assumption to precocious bilingualism (before 6 years old), we think we can make, given the results of our analysis, the hypothesis that the integration of a plurality of languages takes place for individuals before the integration of a cultural plurality which would come between 6 and 12 years old.

According to Vygotsky (1934, 2013), a child's thought development is associated with an inner language. We can therefore wonder if early contact with various languages is not also, beyond the strict linguistic capacity as we have seen with bilingual individuals, an opportunity for the child under development to implement an intercultural thought supported by this intercultural inner language. According to Vygotsky, language is indeed the main mediator for cognition. Schrauf and Rubin (2003), on their side, indicated that bilingual individuals have a language specific self in the way that the self, which is put forward in a given situation, will depend on the language used in that situation.

We initially envisaged that, echoing the results of research in the linguistic field, early interculturation would be formed before the age of 6 years old. However, our quantitative analysis drives us towards the period of life between 6 and 12 years old which would seem significant in the metabolization of plural cultural affiliations.

We can relate this with the corresponding period of life according to Erikson identity development model where the child encounters alterity with the group of peers and enters a process of comparison. It is also the age of primary schooling. Another explanation could be linked to the phenomenon of infantile amnesia which characterizes the period before the age of 6 and "specifically concerns socalled " autobiographical" memories" (Perret, 2011, p. 380). Patrick Perret indicates in this sense : " it appears more and more clearly that the phenomenon described under the term of infantile amnesia could be intrinsically linked to the complex developmental mechanisms which allow the emergence at the same time progressive and late of a true autobiographical memory "(Perret, 2011, p.380).

We think we can make a link with the Proximal Development Zone (PDZ) described by Vygotski as intergroup interculturation would seem to allow the child to develop an intercultural metabolization at the intrapsychic level.

Several terms exist in the literature to qualify this space in the individual's developmental potential : proximal development zone, near development zone, upcoming development zone. These various names identify a potential space, in the children cognitive development, between a lower level representing problems a child can solve alone and a higher level representing problems a child can solve with the help of adults.

We believe that an analysis of Proximal Zone of Intercultural Development (PZID) would be relevant for future research in the field of intercultural psychology as well as that of the theory of mind (Premack and Wooddruff 1978 ; Flavell, 2004 ) as "the mental capacity to infer and understand mental states about oneself and others" (Duval, Piolino, Bejanin, Laisney, Eustache and Desgranges, 2011, p. 
41 ). This theory of mind is the basis of social cognition which mobilizes "a set of mental processes such as the perception of self and of others and the use of knowledge about the rules governing interpersonal interactions to decode the social world" (Duval, Piolino, Bejanin, Laisney, Eustache and Desgranges, 2011 , p. 41 ). This aptitude, which development takes place during childhood, is thus essential for the regulation of individuals' behavior and the proper development of his social interactions, and we might think that interculturation at the intersubjective and intergroup levels could promote it.

As Vygotsky puts it, " the fundamental feature of education is the formation of a proximal development zone. Teaching therefore gives rise to, awakens and animates in the pupil a whole series of internal development processes, which, at a given moment, are only accessible to him within the framework of communication with the adult and collaboration with the comrades, but which, once internalized, will become the pupil's own conquest" (Vygotsky, 1934/2013, p.112).

From a developmental perspective, proximal developmental zone represents what the child is able to reach with the help of those around him. The presence of those around and their interaction opens the way to new development possibilities which the child would not have access to if he was alone. A tension is thus created between abilities the child can acquire alone and others possible, identified thanks to the interaction with the entourage, the group members. This tension, between the child's internal world and the external world, and the concept of the proximal development zone allows Vygotsky to propose for a double movement of human cognitive development, a spontaneous movement of autonomous development and a movement induced by the interaction with the entourage and the tension which emerges from it.

Thus, according to Vygotsky's model, each function in the human psychic would appear twice during his development, the first time as part of a collective activity and therefore as an inter-subjective function, then the second time as an individual and interior activity of the child's thought, as an intrapsychic function.

\section{Conclusion}

If we consider the levels of interculturation that are intrapsychic, intersubjective and intergroupal, we could thus propose that the interculturation process develops first of all in an intersubjective perspective allowing the child to experience contacts with cultures in the context of interaction with those around his, in a collective and social activity. The interculturation process could then develop as an individual and interior activity of the individual's thought. Interculturation would then occur at the intrapsychic level as an integrated characteristic specific to each individual.

The results of our analyzes finally indicate that the reality of interculturation at the intergroup level seems to allow a greater integration of this interculturation at the 
intrapsychic level and it is indeed in this sense that we think of a proximal zone of intercultural development (PZID).

If the interaction with the individual's environment allowed the integration and movement of an intersubjective interculturation towards an intrapsychic interculturation, individuals living in an environment with a significant intergroup interculturation, as this is the case in Singapore, seem to present a greater individual integration of the interculturation process at the intrapsychic level.

\section{Bibliography}

- Ardila, A., \& Ramos, E. (2010). Bilingualism and Aging. Perspectives on Communication Disorders and Sciences in Culturally and Linguistically Diverse Populations, 17(3), 74-81. https://doi.org/10.1044/cds17.3.74

- Ardila, A., \& Ramos, E. (2008). Normal and abnormal aging in bilinguals. Dementia \& Neuropsychologia, 2(4), 242-247. https://doi.org/10.1590/S198057642009DN20400002

- Berry, J. W. (1997). Immigration, Acculturation, and Adaptation. Applied Psychology, 46(1), 5-34. https://doi.org/10.1111/j.1464-0597.1997.tb01087.x

- Camilleri, C. (1990). Identity and cultural diversity management: proposal for a typology. In C. Camilleri, J. Kastersztein, E. Lipianski, H. MalewskaPeyre, I. Taboada-Léonetti et A. Vasquez (Ed.), Identity strategies (p. 85110). Paris : France University Press.

- Clanet, C. (1993). The intercultural: Introduction to intercultural approaches in education and buman sciences (2. ed). Mirail University Press

- Dasen, P. R., \& Perregaux, C. (Éds.). (2002). Why intercultural approabces in education sciences? (1. éd). De Boeck University.

- Denoux, P. (1994). For a new definition of interculturation. In J. Blomart \& B. Krewer (Eds.), Intercultural perspectives (p. 67-81). St Cloud: L'Harmattan.

- Duval, C., Piolino, P., Bejanin, A., Laisney, M., Eustache, F. et Desgranges, B. (2011). The mind theory: conceptual aspects, evaluation and age effect. Revue de neuropsychologie, 3(1), 41-51. doi:10.3917/rne.031.0041.

- Erikson, E.H. (2006/1968). Identity, youth, and crisis. Paris: Flammarion.

- Escafré-Dublet, A. (2015). Immigration and integration in a comparative perspective: Feedback from three european research projects. Espaces et societés, 163(4), 73.

- Flavell, J. (2004). Theory-of-Mind Development: Retrospect and Prospect. MerrillPalmer Quarterly, 50(3), 274-290.

- Licata, L., \& Heine, A. (2012). Introduction to intercultural psychology. De Boeck.

- Oulahal, R. (2019). Interculturation, development and cognition : The intercultural autobiographical memory - An identity and memory constructions analysis in France and in Singapore [PhD]. Toulouse Jean Jaures university, France.

- Oulahal, R. (2021). Interculturation, development and cognition : The intercultural autobiographical memory - An identity and memory constructions analysis in France and in Singapore. Bulletin de psychologie, 571(1), 43-48. https://doi.org/10.3917/bupsy.571.0043 
- Oulahal, R., \& Denoux, P. (2018). Early interculturation, late interculturation. The autobiographical memory in an intercultural life story. L'autre, cliniques, cultures et sociétés, 19(3), 340-343.

- Oulahal, R., \& Denoux, P. (2020). Early Interculturation, Late Interculturation Does It Make a Difference in Our Memories? Journal of Cognition and Culture, 20(1 2), 116 126. https://doi.org/10.1163/15685373-12340077

- Oulahal, R., Denoux, P., \& Teyssier, J. (2018). Place of memory and language in elderly's life story in intercultural situations. NPG Neurologie - Psychiatrie - Gériatrie, 18(103), 13-17. https://doi.org/10.1016/j.npg.2017.09.002

- Oulahal, R., Denoux, P., Teyssier, J., \& Maillet, D. (2018). The knife, the apple and the sheep... Between neuropsychology and intercultural psychology, what perspectives for the cognitive evaluation of episodic memory among non-Frenchspeaking elderly subjects? NPG Neurologie - Psychiatrie - Gériatrie, 18(105), 162-169. https://doi.org/10.1016/j.npg.2018.03.003

- Oulahal, R., Guerraoui, Z., \& Denoux, P. (2018). Between collective memory and diasporic emergence, the case of Algerian descendants in New-Caledonia. Journal de la société des océanistes, 2, 373-382. https://doi.org/10.4000/jso.9237

- Perret, P. (2011). Infantile amnesia : perspective drawn from developmental psychology. Devenir, 23(4), 379. https://doi.org/10.3917/dev.114.0379

- Premack, D., et Woodruff, G. (1978). Does the chimpanzee have a theory of mind? Behavioral and Brain Sciences, 1(4), 515-526. doi:10.1017/S0140525X00076512

- Singleton, D. (2003). Age effect in second language acquisition : preliminary remarks. Acquisition et interaction en langue étrangère, 18, 3-15. https://doi.org/10.4000/aile.2163

- Vygotski, L. S. (1934/2013). Thought and language. La Dispute. 